\title{
Visitas monitoradas ao Museu Paraense Emílio Goeldi, Belém-PA, Brasil
}

\author{
Monitored visits to the Emílio Goeldi Museum, Belém, State of Pará, Brazil
}

Fabricio Lemos de Siqueira Mendes ${ }^{1}$

Helena Doris de Almeida Barbosa ${ }^{2}$

\section{RESUMO}

Os caminhos para minimizar ou erradicar os problemas ambientais têm sido foco de discussões e fóruns desde, pelo menos, a Conferência das Nações Unidas sobre o Ambiente Humano, em 1972. Nas instituições de ensino superior, os projetos de extensão sobre a questão são uma ferramenta importante para a sensibilização da comunidade quanto ao uso racional do ambiente natural, como o projeto "Visitas monitoradas a parques urbanos da Grande Belém-PA". Desenvolvido por docentes e discentes da Faculdade de Turismo da Universidade Federal do Pará (UFPA), em parceria com o Museu Paraense Emílio Goeldi, o projeto tem com o objetivo de planejar e implementar visitas guiadas - e seus desdobramentos - ao parque zoobotânico do Museu Goeldi, bem como preparar os alunos para atuar na instituição, a partir da articulação pesquisa, ensino e extensão. Os resultados evidenciaram participação expressiva de discentes do curso de turismo e visitantes, produção de trabalhos acadêmicos e publicação em revistas científicas. O projeto, pela vivência educativa proposta, pautada na interdisciplinaridade e na associação da teoria com a prática, de maneira formativa, proporciona aos frequentadores do museu maior suporte de informações durante a visita e, por conseguinte, a vivência de novas oportunidades de atuação profissional aos futuros turismólogos.

Palavras-chave: Visitas monitoradas. Parques urbanos. Turismo. Museu Paraense Emílio Goeldi.

\section{ABSTRACT}

The ways to minimize or eradicate environmental problems have been the focus of discussions and forums since, at least, the United Nations Conference on the Human Environment, in 1972. In higher education institutions, extension projects on the issue are an important tool for raising community awareness of the rational use of the natural environment, such as "Monitored visits to urban parks in downtown Belém-PA". The project was developed by professors and students from the Faculty of Tourism of the Federal University of Pará (UFPA), in partnership with the Emílio Goeldi Museum, with the objective of planning and implementing guided tours - and their developments - to the zoobotanical

\footnotetext{
${ }^{1}$ Doutor em Desenvolvimento Socioambiental pela Universidade Federal do Pará, Brasil, com estágio doutoral no Museu Nacional de História Natural de Lisboa, Portugal, e no Museu Zoológico de História Natural da Universidade de Coimbra, Portugal; estágio pós-doutoral na University of Freiburg, Alemanha; professor do Instituto de Ciências Sociais e Aplicada da Universidade Federal do Pará, Brasil; líder do Grupo de Pesquisa Áreas Protegidas da Amazônia: usos e sustentabilidade (GPAPA); membro do Grupo de Pesquisa Biodiversidade, Gestão dos Recursos Naturais e Sociedade no Escudo das Guianas (fabriciolsm@ufpa.br).

2 Doutora em Desenvolvimento Socioambiental pelo Núcleo de Altos Estudos Amazônicos da Universidade Federal do Pará, Brasil; professora colaboradora na mesma instituição e pesquisadora colaboradora do Museu Paraense Emílio Goeldi, Pará, Brasil; membro do Grupo de Pesquisa Gestão, Politicas Públicas e Planejamento em Turismo; Áreas Protegidas da Amazônia: Usos e Sustentabilidade (GPAPA); e Biodiversidade, Gestão dos Recursos Naturais e Sociedade no Escudo das Guianas (hdoris65@gmail.com).
} 
park of the Goeldi Museum, as well as preparing students to work at the institution, based on research, teaching and extension. The results showed an expressive participation of students of the tourism course and visitors, production of academic works and publication in scientific journals. The project, due to the proposed educational experience, based on interdisciplinarity and the association of theory with practice, in a formative way, provides museum visitors with greater information support during the visit and, therefore, the experience of new opportunities for action to future tourism professionals.

Keywords: Monitored visits. Urban parks. Tourism. Emílio Goeldi Museum.

\section{INTRODUÇÃO}

A proteção da natureza, mais precisamente dos recursos naturais, é peça chave para a melhoria da qualidade de vida da sociedade atual e das futuras gerações. É necessário, portanto, buscar alternativas para sensibilizar as pessoas e promover a valorização ambiental, aproximando o indivíduo do ambiente natural, um dos princípios para a sustentabilidade ambiental dos diversos biomas e ecossistemas. Então, deve-se agir de forma previdente em relação ao desenvolvimento sustentável, para que venha a auxiliar a melhoria do grau de comprometimento com a questão ambiental (BRITO; CÂMARA, 1998).

Na contramão da sustentabilidade e da preservação, a Amazônia vive uma crise ambiental decorrente de sua ocupação predatória, induzida por programas governamentais e projetos da iniciativa privada pautados por uma lógica de substituição de espaços naturais tradicionalmente ocupados e/ou utilizados por populações indígenas e ribeirinhas - por atividades de alto grau de antropia, como a mineração e o desmatamento florestal (ABRAMOVAY, 2019). Como resultado desse processo, Magnusson et al. (2016, p. 115) alertam que:

Apesar de sua imensa biodiversidade, a Amazônia sofre com algumas das desigualdades sociais mais agudas do país. Enquanto alguns centros, como Manaus e Belém, são tecnologicamente avançados e possuem alto índice de desenvolvimento humano, comunidades distantes dessas localidades apresentam índice de desenvolvimento humano muito baixo, altas taxas de analfabetismo e altos índices de mortalidade infantil.

A política desenvolvimentista elaborada nos últimos anos para a Amazônia fomentou, além da diminuição da biodiversidade, o surgimento de atores sociais - grileiros, garimpeiros, caçadores - que, segundo Abramovay (2019), atuam em uma rede de articulações alicerçadas em atividades ilegais e na violência, o que aumenta a criminalidade e dissemina a insegurança por toda a região. $\mathrm{O}$ resultado desse processo é o profundo desequilíbrio nos ecossistemas naturais amazônicos. O insucesso da ação do Estado e a exploração abusiva praticada pelo 
empresariado refletem-se nas precárias condições de vida da população tradicional local e no alto índice de desmatamento dos biomas da região.

Os problemas que afligem a sociedade não devem ser analisados de forma isolada, pois derivam de um conjunto de fatores cumulativos e simultâneos, de uma variedade de decisões e posturas adotadas por seus membros. De acordo com Quaresma (2003), as questões relativas ao ambiente têm sido alvo de políticas imediatistas e clientelistas, fruto da pressão de agentes externos, a serviço do capital nacional e internacional. Encontrar alternativas para superar/minimizar as consequências desse processo é um dos grandes desafios que as instituições de ensino superior (IES) têm enfrentado, especialmente as da região amazônica, tanto na área da pesquisa, como no ensino e na extensão.

Nesse contexto, vale lembrar que a característica mais marcante da Amazônia é a biodiversidade: a região abriga cerca de sessenta mil espécies de plantas superiores, dois milhões e meio de artrópodes, duas mil espécies de peixes e trezentas espécies de mamíferos (IBGE, 2017).

A quantidade de espécies animais e vegetais cria pelo menos em termos potenciais a possibilidade de exploração econômica para diferentes usos em cadeias produtivas relacionadas a diversos setores produtivos, como os setores de base florestal: madeireiro e não-madeireiro, do qual pode-se incluir, também, a atividade extrativa vegetal; alimentos e bebidas; aproveitamento de biomassa; higiene pessoal e cosméticos; fármacos e medicamentos, incluindo, fitoterápicos; entre muitos outros. (DINIZ et al., 2017, p. 1).

Associados a essas atividades, pode-se inserir o lazer e o turismo como possibilidades de uso desse ecossistema. O turismo, uma das vertentes do lazer, tem um caráter multi e interdisciplinar que possibilita não somente o diálogo entre áreas de conhecimento distintas, mas também permite interligar diferentes áreas de atuação. Produto social, o turismo dinamiza o desenvolvimento econômico, sustentável, social e ambiental; logo, as discussões sobre o turismo responsável e as possibilidades de se articular as perspectivas sociais e ambientais a partir da práxis turística estão se tornando mais presentes em fóruns, políticas públicas e iniciativas comunitárias. Nesse processo, urge a presença da educação como fio condutor para o planejamento e a prática turística, em particular aquela vinculada aos ambientes naturais em suas diversas categorias, especialmente em áreas protegidas, como é o caso dos parques urbanos. 
$\mathrm{O}$ conceito de parque urbano (PU) ainda não encontrou consenso entre os pesquisadores. Nesse relato, para fins didáticos, entende-se PU como

espaço público de socialização e aprendizado. Em consonância com o SNUC [Sistema Nacional de Unidades de Conservação], que rege as diretrizes para o uso de uma UC [unidade de conservação] na legislação ambiental brasileira, seu uso deve ser restrito pelos atores sociais, sendo admitida apenas a permissão de uso público em espaços destinados às atividades de educação e interpretação ambiental, uso lúdico e cultural com fins de preservação dos recursos naturais no ambiente urbano. (CARDOSO; SOBRINHO; VASCONCELLOS, 2015, p. 77).

Esses espaços, com múltiplos usos, vêm sendo demandados por um contingente populacional significativo e diversificado. Entretanto, por limitações orçamentarias e humanas, geralmente são subutilizados tanto em relação ao conhecimento que encerram e podem transmitir quanto ao uso de novas tecnologias para melhoria do monitoramento das visitas.

Muitos desses espaços acabam exercendo funções para além da proteção ambiental, pois se tornam palco de educação formal e informal, de memórias, de sociabilidade, de saúde, ludicidade e difusão patrimonial. O turismo também os utiliza como atrativo e produto representativo de uma dada realidade, muitas vezes diversa da vivenciada pelo turista. A propósito da definição dos termos, embora sua acepção seja mais ampla, o turista será considerado aqui como o público oriundo de outros municípios que acessa os PU. Visitante, por sua vez, corresponde aqui ao público que frequenta os parques públicos de sua própria cidade.

Para se sentirem motivados a visitar determinado local, turistas e visitantes devem ser estimulados a se deslocar até o ponto turístico, principalmente aos espaços naturais. No entanto, para que se possa divulgar um determinado parque, ele deve contar com estrutura, serviços e acessibilidade. Daí a importância de se inserir a educação ambiental (EA) no planejamento desses espaços, dos PU em especial, pois a maioria de seus visitantes não é incentivada a respeitar e zelar pelos ambientes naturais, considerando que o desrespeito ao meio ambiente é o comportamento padrão que se espera, lamentavelmente, por conta do distanciamento entre o indivíduo do século 21 e o ambiente natural, da visão deturpada de que a natureza sempre deve ser subjugada pelo ser humano, e da falta de informação, o que impede a formação do sentimento de pertencimento por esses espaços. Os PU são diretamente afetados pela falta de EA aos turistas, que, em muitos casos, causam danos estruturais aos parques, alguns irreversíveis. 
Entre as várias vertentes do turismo relacionadas à questão ambiental, destacam-se duas: Ecoturismo e Turismo Pedagógico. O Ecoturismo pode contribuir para a conservação da natureza de modo mais eficaz e gratificante, desde que haja a participação efetiva da sociedade, assim como a formação de profissionais qualificados para atuarem em ambientes naturais (COSTA, 2002). Já o Turismo Pedagógico configura-se uma atividade extraclasse que compreende visitas monitoradas em locais previamente agendados, cujo objetivo é mostrar aos visitantes/discentes a relação do meio com o seu cotidiano (SCREMIN; JUNQUEIRA, 2012). Ambas as vertentes podem ser utilizadas como ferramenta complementar ao ensino formal, abrangendo diferentes disciplinas de maneira transversal.

Com base nessas discussões, foi desenvolvido, por docentes e discentes da Faculdade de Turismo da Universidade Federal do Pará (UFPA), o projeto de extensão "Visitas Monitoradas a Parques Urbanos da Grande Belém (PA)" (VMPU). Coadunado à missão da $\mathrm{UFPA}^{3}$, o projeto tem como objetivo promover a integração entre a academia e a comunidade, por meio de visitas monitoradas a parques urbanos, tendo como fio condutor a educação ambiental, a ecologia, a zoologia e o patrimônio, áreas temáticas trabalhadas ao longo da graduação. A partir da realidade do Parque Zoobotânico do Museu Paraense Emílio Goeldi (MPEG), o projeto associa teoria e prática ao proporcionar aos frequentadores do parque uma visita responsável, para além da contemplação, associando lazer ${ }^{4}$, informação e valorização da natureza.

O VMPU é um exemplo da relevância e das muitas possibilidades criadas pelos projetos de extensão elaborados nas IES de levar o conhecimento produzido nessas instituições à sociedade, cumprindo, assim, um de seus papéis. Tal saber não deve se restringir aos campi onde são gerados, mas se expandir para a comunidade em uma relação dialética, na qual o discente tem a oportunidade de vivenciar a teoria e a prática, bem como "o conhecimento objetivo da realidade social" (UFPA, 2020). Essas possibilidades contribuem para a formação acadêmica e cidadã dos discentes, e consolidam a atuação das IES para a inclusão e a busca por equidade e justiça social.

\footnotetext{
3 "Produzir, socializar e transformar o conhecimento na Amazônia para a formação de cidadãos capazes de promover a construção de uma sociedade inclusiva e sustentável” (UFPA, 2020).

4 "Definimos então o lazer como um conjunto de atividades de recreação realizadas em um tempo residual dos seres humanos [...]. Além disso, o lazer é considerado como tendo a função de renovar a força de trabalho, ou seja, promover o descanso dos trabalhadores, necessário para que voltem a trabalhar em plenas condições" (ORIO, 2018, p. 115).
} 
Esse artigo tem como objetivo socializar a experiência do primeiro ano de aplicação do VMPU, realizado no Parque Zoobotânico do Museu Goeldi. Por meio da articulação de temas ambientais, históricos e socioculturais, o projeto expôs a importância da preservação e conservação da natureza local, não só para os turistas que visitam aquele espaço, como também para os moradores que o frequentam.

O projeto, assim como esse relato, foram pautados pelas experiências relatadas por Morais et al. (2018) sobre as ações desenvolvidas nos museus de Recife; Fonseca et al. (2018), acerca das atividades de educação ambiental voltadas para estudantes de escolas públicas de Minas Gerais, a partir da avifauna da região; Nascimento, Santos e Nunes (2016), que tratam dos problemas ambientais de Santo Antão, em Pernambuco, a partir da produção de dejetos; Schneider et al. (2018), que trabalham com a questão do uso dos espaços verdes por crianças e adolescentes de Florianópolis; Hernandez e Hock (2016), que debatem a importância da conservação e educação ambiental a partir de estudos desenvolvidos por universidades sobre os insetos do Parque Ecológico do Córrego Grande, em Santa Catarina.

\section{METODOLOGIA}

\section{A) Local de realização do PE: MPEG}

A Faculdade de Turismo da UFPA aprovou, em 2016, a realização do PE "Visitas Monitoradas a Parques Urbanos da Grande Belém (PA)”, em vigência até 2020. Por conseguinte, o projeto foi submetido e aprovado em editais anuais da UFPA, sob a responsabilidade da Pró-reitoria de Extensão (PROEX), os quais preveem a reserva de uma bolsa de extensão anual e a participação de outros discentes não bolsistas (voluntários), coordenados por dois docentes: um(a) coordenador(a) e um(a) colaborador(a). Ao longo de seus cinco anos de execução, o VMPU contou com a participação de 60 alunos.

A elaboração do projeto foi conduzida pela tríade pesquisa, ensino e extensão, tendo como ponto de partida o levantamento dos PU, legalmente constituídos, existentes no município de Belém. Depois de elencados os que se encontravam em situação regular de visitação, foi escolhido o PU que seria o lócus do projeto, sendo, então, selecionado o MPEG, vinculado ao Ministério da Ciência, Tecnologia, Inovações e Comunicações (MCTIC). Essa seleção foi subsidiada por alguns fatores: a vivência dos docentes no MPEG; a sua localização no centro 
de Belém; o fato de ser um dos principais espaços de visitação pública da cidade; e por sua longevidade.

O Parque Zoobotânico do MPEG é o mais antigo jardim zoológico do Brasil, criado em 1895 por Emílio Goeldi ${ }^{5}$ :

Em pouco mais de dez anos, o zoólogo e sua equipe transformaram uma residência de férias ou temporadas, localizada na periferia da cidade de Belém, no primeiro e mais importante jardim zoológico do Brasil, posto que ocupa até avançado o século XX. A construção de um zoológico e de um horto botânico como anexos do museu estava nos planos de Goeldi e do governador do Pará, Lauro Sodré, desde o início. Ambos foram concebidos com fins didáticos, como se fossem uma "escola de intuição das obras da natureza amazônica para o público". (SANJAD et al., 2012, p. 200).

Além disso, o MPEG é um dos maiores museus de história natural do Brasil, sendo considerado a maior instituição científica da Amazônia e um dos mais importantes centros de pesquisa do mundo. Apesar de o Parque Zoobotânico ser o espaço mais conhecido e mais visitado do MPEG, o museu também possui um campus de pesquisa e a Estação Científica Ferreira Penna.

O campus de pesquisa, que funciona desde 1978 e está situado na Avenida Perimetral, bairro da Terra Firme, em Belém, possui 17 coleções científicas nas áreas da botânica, zoologia, arqueologia, etnografia, linguística, paleontologia, minerais e rochas. Além disso, abriga laboratórios, as coordenações de pesquisa e planejamento do MPEG, a biblioteca Domingos Soares Ferreira Penna, o arquivo Guilherme de La Penha, o Núcleo de Inovação e Transferência de Tecnologia (NITT) e cursos de pós-graduação stricto sensu, em convênio com a UFPA. Todas essas instalações proporcionam ações diversificadas de educação com os centros comunitários.

A Estação Científica Ferreira Penna (ECFPn) foi construída em 1993, por meio de parceria do MPEG com o Instituto Brasileiro do Meio Ambiente e dos Recursos Naturais (IBAMA), em uma área de aproximadamente $3.000 \mathrm{~m}^{2}$ dentro da Floresta Nacional de Caxiuanã (PA). O objetivo da ECFPn é promover atividades de EA, apoiar estudos sobre a biodiversidade amazônica e incentivar pesquisas da comunidade em geral.

Localizado no bairro de São Brás, centro de Belém, o Parque Zoobotânico do Museu Goeldi (Figura 1) possui uma extensão de 5,4 hectares e foi fundado com o intuito de conservar e

\footnotetext{
${ }^{5}$ Emil August Göldi ou Emílio Augusto Goeldi (1859-1917) foi um zoólogo suíço que desenvolveu relevante trabalho à frente do MPEG.
} 
divulgar os estudos adquiridos sobre a região amazônica. O parque é aberto ao público de terça a domingo e comporta recintos que abrigam algumas espécies de animais, bem como monumentos históricos e exemplares da fauna e flora amazônica que retratam a realidade da biodiversidade da região e atraem visitantes, turistas e pesquisadores do mundo todo.

Figura 1 - Aspecto das trilhas internas do parque do MPEG

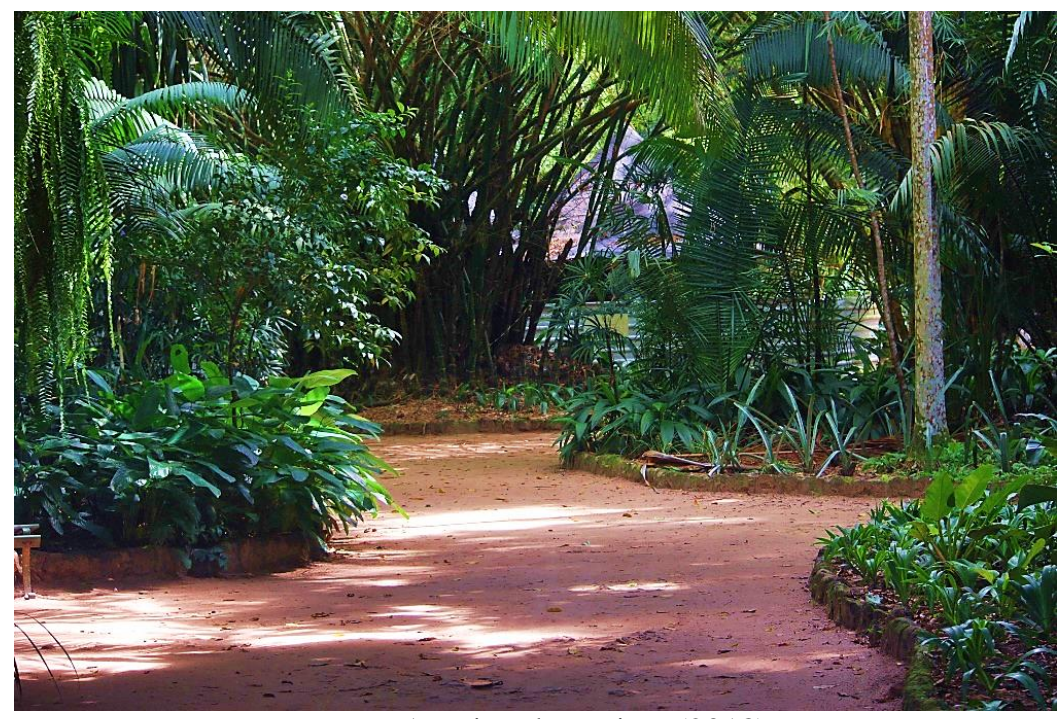

Fonte: Arquivo do projeto (2018)

No parque estão localizadas a Diretoria do Museu Goeldi, as coordenações de Comunicação e Extensão, Administração e Museologia, os serviços do Parque Zoobotânico e da Comunicação Social, o Núcleo Editorial de Livros, o Aquário Jacques Huber, a Biblioteca Clara Maria Galvão e o Pavilhão de Exposições Temporárias Rocinha.

B) O projeto

As ações do VMPU foram iniciadas a partir da assinatura do Termo de Cooperação Técnica entre o MPEG e a UFPA, publicado no Diário Oficial da União (BRASIL, 2016). Internamente houve o processo de seleção do bolsista e dos voluntários, os quais foram apresentados à equipe técnica do MPEG, que procedeu à capacitação dos integrantes do projeto (Figura 2). Durante a capacitação, os docentes responsáveis pelo VMPU abordaram temas como relações interpessoais e atendimento ao público, enquanto os técnicos do MPEG discorreram sobre o conhecimento da estrutura institucional do museu, suas áreas de atuação e o acervo do parque zoobotânico, perpassando as áreas de botânica, zoologia, ciências humanas e ciências da terra. 
Figura 2 - Discentes do VMPU em capacitação por técnico do MPEG

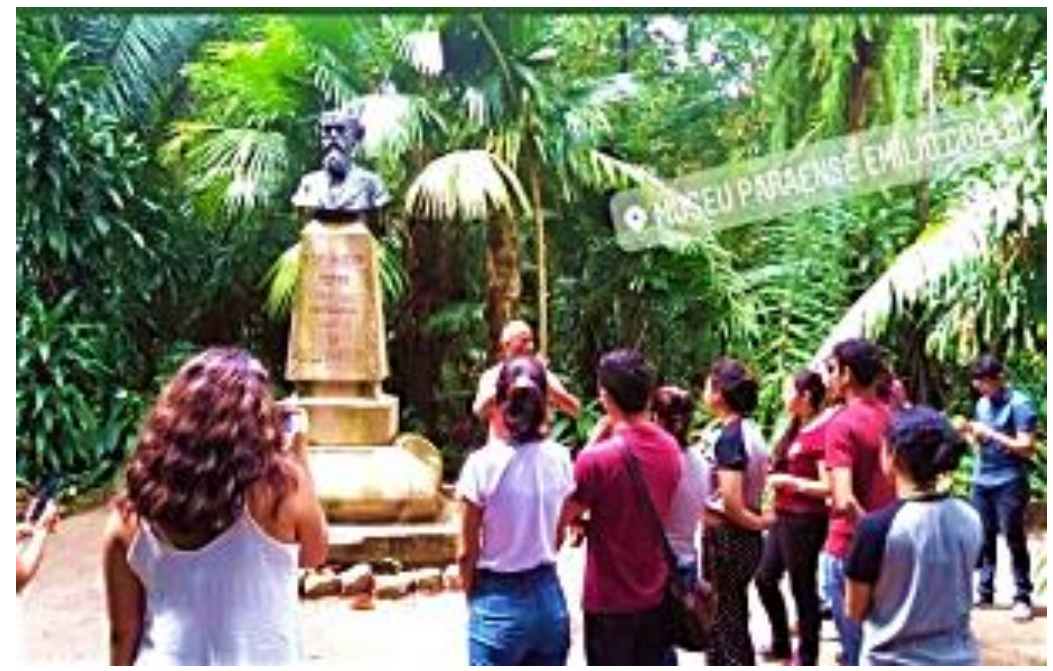

Fonte: Arquivo do projeto (2016).

As atividades do projeto se estruturaram em visitas monitoradas ao parque (Figura 3), participação nos eventos voltados para o público do MPEG, monitoria no aquário e em exposições, levantamento de dados relativos aos visitantes e atendimento a escolas (quando solicitados). Essas atividades se realizaram no espaço institucional do MPEG.

Figura 3 - Bolsista do VMPU conduzindo visitantes do MPEG

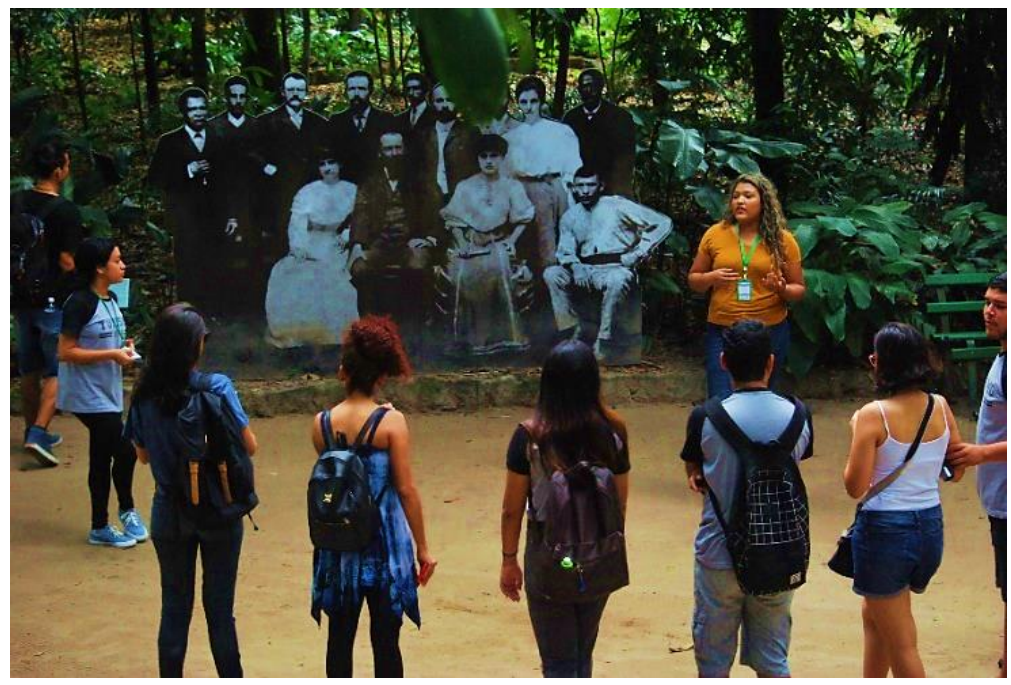

Fonte: Arquivo do projeto (2019).

Fora do museu, ocorriam seminários mensais na UFPA (Figura 4), quando eram debatidos textos acadêmicos e experiências com temáticas relacionadas à $\mathrm{EA}$, ao turismo e à sociobiodiversidade, à história, ecologia, entre outros. O projeto também foi espaço para estágios supervisionados e objeto de trabalhos de conclusão de curso, além de seus discentes terem elaborado pesquisas e artigos para serem apresentados em eventos locais e nacionais. 
Figura 4 - Seminário do VMPU na UFPA

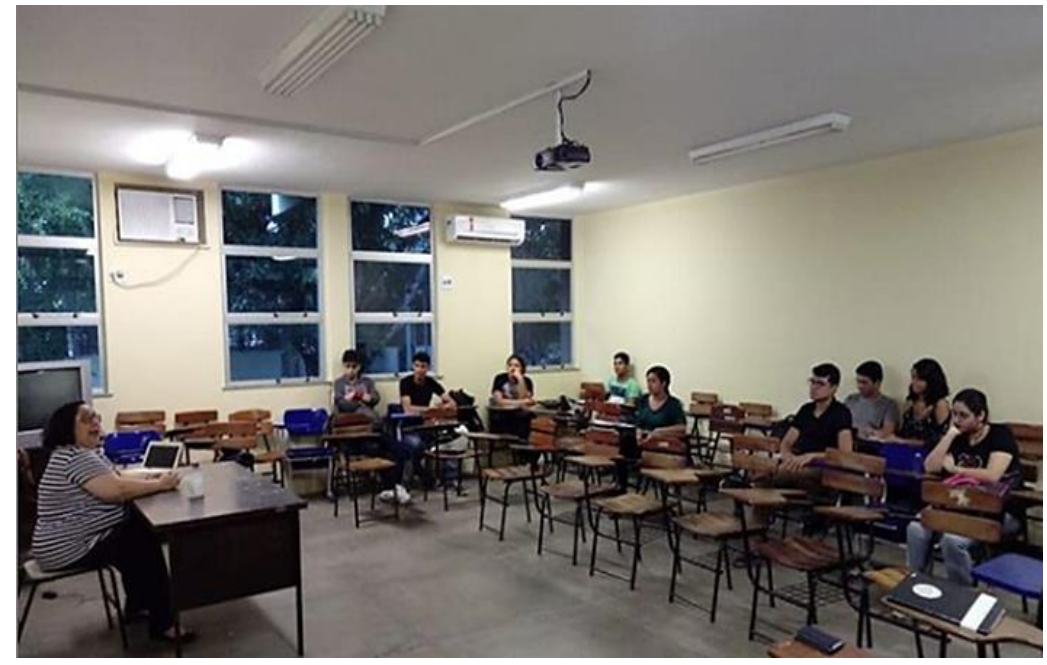

Fonte: Arquivo do projeto (2019)

Com o decorrer do projeto, os discentes perceberam a necessidade de desenvolver uma trilha alternativa no parque zoobotânico (Figura 5) pela qual os visitantes e turistas pudessem encontrar os principais atrativos do parque. A trilha desenvolvida foi elaborada a partir de temas antropológicos, zoológicos e botânicos, a fim de oferecer uma visita mais sistematizada, com menor tempo do percurso, o que possibilitará aos frequentadores do parque um tempo livre após a visita monitorada.

Figura 5 - Panfleto da trilha elaborada pelos discentes do VMPU

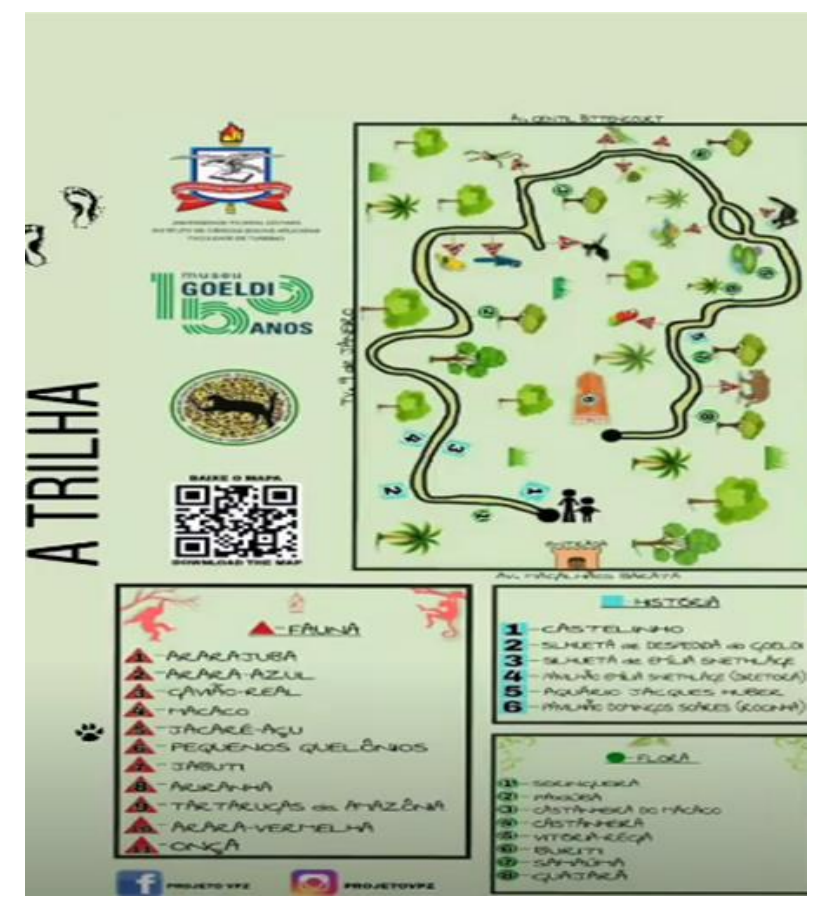

Fonte: Arquivo do projeto (2017). 
Desse modo, ficaram estabelecidas duas visitas monitoradas pela trilha, em cada turno, totalizando 40 minutos: às 9h30 e às $11 \mathrm{~h}$, pela manhã; e às $14 \mathrm{~h} 30$ e outra às $16 \mathrm{~h}$, pela tarde. Aos finais de semana e feriados, quando a demanda é bem maior, ocorriam duas visitas monitoradas simultaneamente, sempre que necessário. Essas visitas eram identificadas por um banner (Figura 6) instalado no portão de entrada do MPEG.

Figura 6 - Horário de visitas do VMPU

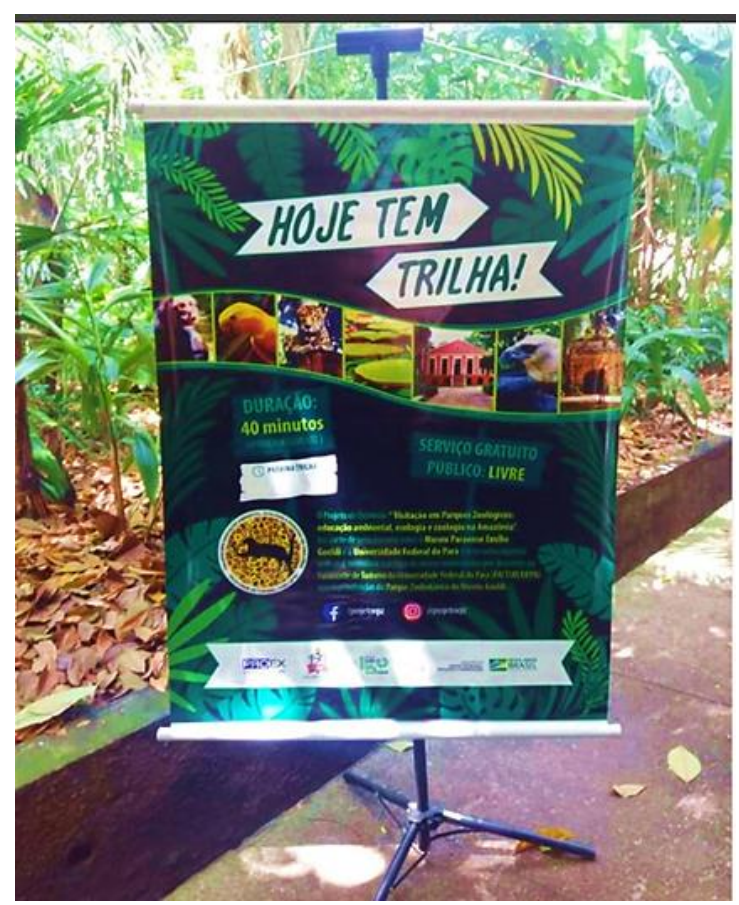

Fonte: Arquivo do projeto (2017).

Em decorrência do bom trabalho desenvolvido, principalmente por parte dos discentes, o VMPU obteve boa repercussão nos meios de comunicação da sua cidade-sede, tendo suas atividades registradas e veiculadas por programas de televisão e rádio, assim como em matérias de sites e jornais.

O objetivo do VMPU de incentivar a prática de visitas monitoradas em PU pela articulação de temas ambientais, expondo a importância da preservação e conservação da natureza local, destaca a sua relevância à cidade como um todo, na medida em que transmite à sociedade o conhecimento aprendido na academia sobre a diversidade amazônica. A Faculdade de Turismo da UFPA pretende continuar aproximando a comunidade acadêmica da sociedade por meio de práticas ambientais, evidenciando que o acesso ao patrimônio ambiental e cultural é um direito de todos - não somente de turistas, mas também dos moradores de Belém. 


\section{RESULTADOS}

As visitas monitoradas nas dependências internas do parque zoobotânico do MPEG foram não apenas eficazes, mas também frutíferas. O Quadro 1 apresenta, além do número de discentes da Faculdade de Turismo que participaram do projeto, tanto como bolsista e não bolsista, e de discentes que realizaram seu estágio obrigatório, previsto no Plano Pedagógico do Curso de Turismo da UFPA, o número de trabalhos acadêmicos expostos em eventos locais e nacionais baseados no projeto, assim como as publicações em revistas científicas e ações de divulgação em mídias sociais e impressa jornalística sobre o VMPU.

Quadro 1 - Quantitativo dos resultados do projeto VMPU

\begin{tabular}{|l|c|}
\hline ATIVIDADES & $\mathbf{2 0 1 6 - 2 0 2 0}$ \\
\hline Discentes bolsistas & 05 \\
\hline Discentes não bolsistas & 40 \\
\hline Discentes em estágios obrigatórios & 15 \\
\hline Trabalhos acadêmicos locais & 05 \\
\hline Trabalhos acadêmicos nacionais & 05 \\
\hline Publicações em revistas científicas & 01 \\
\hline Ações de divulgação & 06 \\
\hline Visitantes & $\sim 2.000$ \\
\hline
\end{tabular}

Fonte: Arquivo do projeto (2020).

Não é possível identificar o número exato de visitantes que foram conduzidos ao longo do projeto, visto que muitos não assinaram o Livro de Visitas. Sobre os trabalhos acadêmicos desenvolvidos pelos discentes que participaram do VMPU, a seguir estão listados seus títulos e local de apresentação:

a) O Aquário Jacques Huber e sua Representatividade Local como Forma de Lazer - III Congresso Brasileiro de Estudos do Laser (Campo Grande, MT);

b) Visitação em Parque Zoológico: Educação Ambiental, Ecologia e Zoologia na Amazônia - Congresso Brasileiro de Extensão Universitária (Natal, RN);

c) Perfil e Vivências de Lazer: Os Visitantes do Parque Zoobotânico do Museu Paraense 
Emílio Goeldi-Belém/PA - Associação Brasileira de Turismo (Joinville, SC);

d) Projeto de Extensão VMPU - Apresentação oral no Campus Serra da Capivara da Universidade Federal do Vale do São Francisco (São Raimundo Nonato, PI);

e) O Parque Zoobotânico Museu Paraense Emílio Goeldi na Visão dos Turistas - II Encontro de Uso Público em Áreas Protegidas (Belém, PA);

f) Planejamento e Implantação de Trilhas no Parque Zoobotânico, Museu Paraense Emílio Goeldi, Pará, Brasil - II Encontro de Uso Público em Áreas Protegidas (Belém, PA);

g) Projeto Visitação em Parque Zoológico: Educação Ambiental, Ecologia e Zoologia na Amazônia - II Seminário Conexões ICSA/UFPA (Belém, PA);

h) Turismo de Observação: A Percepção dos Visitantes sobre o Aquário Jacques Huber do Parque Zoobotânico do Museu Paraense Emílio Goeldi - Trabalho de Conclusão de Curso apresentado à UFPA (Belém, PA).

Os resultados apresentados, assim como o trabalho comprometido realizado pelos discentes e equipe técnica, têm incentivado novos alunos do Curso de Turismo da UFPA a participarem do projeto. De fato, ao longo dos anos, as vagas são sempre preenchidas e a avaliação dos que passam pelo VMPU são sempre positivas. Esses dados ressaltam a importância da continuidade do projeto.

A extensão e o voluntariado vêm sendo percebidos e valorizados de maneira diferenciada pela sociedade e pelo setor empresarial. De acordo com Domeneghetti (2001), o século 21 deverá se caracterizar pelo reconhecimento da importância das prioridades sociais. Assim, projetos extensionistas e o voluntariado se configuram como alternativas para atender a essas prioridades por praticarem ações que o Estado não consegue realizar.

Cuevas et al. afirmam que "el voluntariado representa una actividad social que permite contribuir a diversos fines, tanto para los actores que ejercen la función denominados voluntarios, como para los participantes sociales que reciben sus servicios" $\left(2015\right.$, p. 49) ${ }^{6}$. A experiência extensionista fornece ao discente não só a prática da teoria presente nos

\footnotetext{
${ }^{6} \mathrm{O}$ voluntariado representa uma atividade social que permite que você contribua para vários propósitos, tanto para os atores que exercem a função denominada voluntários, quanto para os participantes sociais que recebem seus serviços.
} 
componentes curriculares dos cursos, mas também o exercício de outras habilidades, como criatividade, inovação, liderança, agregação e, no caso do VMPU, articulação de ações no contexto socioambiental.

\section{CONSIDERAÇÕES FINAIS}

Desde a sua criação em 2016, o PE VMPU tem atingido os objetivos a que se propôs, sempre atrelados à missão da UFPA. O projeto se consolidou como veículo de informação aos frequentadores do MPEG, como ferramenta de troca cultural entre os atores envolvidos no projeto e de efetivação de ações cidadãs. Associado a isso, vem colaborando com a sensibilização ambiental ao expor a necessidade do cuidado e a fragilidade do ambiente natural.

O VMPU tem ajudado a chamar a atenção da sociedade para os projetos de extensão e, por conseguinte, a mostrar a presença e atuação da universidade na comunidade. Fóruns e eventos criados para debater as ações extensionistas em âmbito local, regional e nacional, revistas especializadas, matérias divulgadas na mídia e em sites têm contribuído para aproximar ainda mais as IES da sociedade, norteada por um sentimento de inclusão e pertencimento. Entretanto, as ações extensionistas das IES devem ser ampliadas, principalmente as que contemplam parcerias interinstitucionais, para que se alcance um público cada vez maior e mais heterogêneo. Para tanto, programas entre diferentes unidades da universidade poderiam ser fomentados, promovendo a transdisciplinaridade teórica e prática.

Quanto à formação acadêmica, o VMPU superou as expectativas ao envolver um número significativo de estudantes da graduação, que se dedicaram de fato ao projeto, engajando-se de maneira comprometida e inovadora. O acadêmico de turismo tem a oportunidade de vivenciar perspectivas de outras áreas de atuação profissional a partir da coadunação do lazer, do turismo e da questão ambiental presentes no PU, além da possibilidade da prática de outros idiomas ao interagir com visitantes estrangeiros.

Portanto, os objetivos do projeto foram alcançados, uma vez que a avaliação dos visitantes foi positiva, assim como a dos bolsistas do projeto que avaliaram a participação no projeto como excelente. Devem ser levadas em conta também as avaliações das bancas do Seminário de Ensino, Pesquisa e Extensão da UFPA, pois durante os anos em que o projeto foi apresentado, sempre recebeu elogios. 
Ações futuras do VMPU estão planejadas com fins de ampliar sua atuação na cidade e alcançar outro PU de Belém, o Jardim Botânico Bosque Rodrigues Alves, um fragmento de floresta nativa de 15 hectares, transformado em área protegida em 1883. Sob a administração da Prefeitura de Belém, o Bosque também é parte do capital simbólico da população belenense.

\section{REFERÊNCIAS}

ABRAMOVAY, R. Amazônia: por uma economia do conhecimento da natureza. São Paulo: Elefante, 2019.

BRASIL. Diário Oficial da União. Pró-Reitoria de Planejamento, Extrato de Acordo de Cooperação, Universidade Federal do Pará. Sessão 3, nº. 222, 2016.

BRITO, F. A.; CÂMARA, J. B. D. Democratização e gestão ambiental: em busca do desenvolvimento sustentável. Rio de Janeiro: Vozes, 1998.

CARDOSO, S. L. C.; SOBRINHO, M. V.; VASCONCELLOS, A. M. A. Gestão ambiental de parques urbanos: o caso do Parque Ecológico do Município de Belém Gunnar Vingren.

URBE, Curitiba, v. 7, n. 1, p. 74-90, jan./abr. 2015. Disponível em: https://www.scielo.br/pdf/urbe/v7n1/2175-3369-urbe-7-1-0074.pdf. Acesso em: 14 maio 2020. Doi: 10.1590/2175-3369.007.001.AO05.

COSTA, P. C. P. da. Reflexões finais: a real contribuição do ecoturismo para a natureza. In: NEIMAN, Z. (org.). Meio ambiente, educação ambiental e ecoturismo. São Paulo: Manole, 2002. p. 177-181.

CUEVAS, M. et al. Motivación de un grupo de voluntarios afiliados a dos organizaciones sin fines de lucro del área sur de Puerto Rico. Informes Psicológicos, Medellín, v. 15, n. 1, p. 4761, 2015. Disponível em: http://dx.doi.org/10.18566/infpsicv15n1a03. Acesso em: 6 jul. 2020. Doi: 10.18566/infpsicv15n1a03.

DINIZ, M. B. et al. Região Amazônica: biodiversidade e possibilidades de transformação industrial. Cadernos CEPEC, Belém, v. 6, n. 5, mai. 2017. Disponível em: https://periodicos.ufpa.br/index.php/cepec/article/view/7037/5487. Acesso em: 6 jul. 2020. Doi: 10.18542/cepec.v6i1-6.7037.

DOMENEGHETTI, A. M. Voluntariado: gestão do trabalho voluntário em organizações sem fins lucrativos. São Paulo: Esfera, 2001.

FONSECA, A. R. et al. Aves em liberdade: solte essa ideia!: relato de ações extensionistas voltadas para a preservação ambiental. Em Extensão, Uberlândia, v. 17, n. 1, p. 225-242, jan./jun. 2018. Disponível em:

http://www.seer.ufu.br/index.php/revextensao/article/view/41104/pdf. Acesso em: 6 jul 2020. Doi: 10.14393/REE-v17n12018-rel11.

HERNANDEZ, M. I. M.; HOCH, D. H. Diversidade de insetos do parque ecológico do 
Córrego Grande: educação ambiental e conservação. Extensio, Florianópolis, v. 13, n. 21, p. 43-55, 2016. Disponível em: https://periodicos.ufsc.br/index.php/extensio/article/view/18070221.2016v13n22p43/0. Acesso em: 6 jul. 2020. Doi: 10.5007/1807-0221.2016v13n22p43.

IBGE. Centro de Documentação e Disseminação de Informações. Fauna ameaçada de extinção. Rio de Janeiro: IBGE, 2001.

MAGNUSSON, W. E. et al. Amazônia: biodiversidade incontável. In: PEIXOTO, A. L.; LUZ, J. R. P.; BRITO, M. A. de. (org.). Conhecendo a biodiversidade. Brasília: CNPq; MCTIC; PPBio, 2016. p. 112-123. Disponível em:

https://ppbio.inpa.gov.br/sites/default/files/conhecendo_a_biodiversidade_livro.pdf. Acesso em: 6 jul. 2020.

MORAIS, I. A. L. et al. Circuito de museus: a experiência em Recife, Pernambuco, Brasil (2016). Em Extensão, Uberlândia, v. 17, n. 1, p. 131-152, jan./jun. 2018. Disponível em: http://www.seer.ufu.br/index.php/revextensao/article/view/40216. Acesso em: 6 jul. 2020. Doi: 10.14393/REE-v17n12018-rel04.

NASCIMENTO, A. T. B. da S.; SANTOS, I. F.; NUNES, J. R. V. Oficinas educativas/reflexivas e a interface com saúde e o meio ambiente. Em Extensão, Uberlândia, v. 18, n. 1, p. 134-144, jan./jun. 2019. Disponível em:

http://www.seer.ufu.br/index.php/revextensao/article/view/44977. Acesso em: 6 jul. 2020. Doi: 10.14393/REE-v18n12019-44977.

ORIO, M. V. Diversão e classes sociais: o significado do lazer na sociedade capitalista. Despierta, Naviraí, Ano 5, n. 5, p. 113-130, 2018. Disponível em: https://redelp.net/revistas/index.php/rde/article/view/821/735. Acesso em: 14 maio 2020.

QUARESMA, H. D. A. B. O desencanto da princesa: pescadores tradicionais e turismo na área de proteção ambiental de Algodoal/Maiandeua. Belém: NAEA, 2003.

SANJAD, N. et al. Documentos para a história do mais antigo jardim zoológico do Brasil: o Parque Zoobotânico do Museu Goeldi. Bol. Mus. Para. Emílio Goeldi. Ciênc. Hum, Belém, v. 7, n. 1, p. 197-258, jan./abr. 2012. Disponível em: https://www.scielo.br/scielo.php?script=sci_arttext\&pid=S1981-81222012000100013. Acesso em: 15 maio 2020. Doi: 10.1590/S1981-81222012000100013.

SCHNEIDER, J. et al. Projeto natureza nossa: um relato de experiência. Extensio, Florianópolis, v. 15, n. 31, p. 94-105, 2018. Disponível em: https://periodicos.ufsc.br/index.php/extensio/article/view/1807-0221.2018v15n31p94. Acesso em: 7 jul. 2020. Doi: 10.5007/1807-0221.2018v15n31p94.

SCREMIN, J.; JUNQUEIRA, S. Aprendizado diferenciado: turismo pedagógico no âmbito escolar. Caderno de Estudos e Pesquisas do Turismo, Curitiba, v. 1, p. 26-42, jan./dez. 2012.

UFPA. Missão, visão, princípios. Disponível em: https://portal.ufpa.br/index.php/missaovisao-principios. Acesso em: 13 maio 2020.

Submetido em 23 de maio de 2020. Aprovado em 26 de junho de 2020. 